\title{
The Relationship Between the Adequacy of Rewards and Employee Performance in Large Beverage Companies: A Comparative Study
}

\author{
Felicidad A. Dy Kam, DBA \\ Assistant Professor, Department of Management and Human Resources, College of Financial Sciences, \\ AMA International University-Bahrain, Salmabad, Kingdom of Bahrain
}

\begin{abstract}
This research study aimed to look into the relationship between the adequacy of company rewards and employee performance as perceived by the employees of Coca-Cola Bottlers Phils., Inc. in Meycauayan, Bulacan and Cosmos bottling Corporation in Valenzuela Metro Manila. The respondents of the study were the 35 employees of Cosmos Bottling Corporation and 22 employees Coca-Cola Bottling Corporation. The researcher extensively used the survey questionnaire for data gathering and employed statistical tools such as Weighted Mean, T-test and Pearson R. The findings revealed that the adequacy of rewards between the two groups of employees ranged from barely adequate to adequate. There was a significant difference in the adequacy of rewards as perceived by the two groups of respondents. The findings also disclosed that there was a significant relationship in the adequacy of rewards and employee performance as revealed by the respondents of the two beverage companies
\end{abstract}

Keywords: Adequacy, reward, Coca-cola employees, Cosmos employees

\section{INTRODUCTION}

One of the most difficult functions of personnel management is that of determining rates of monetary compensation. Not only it is one of the most complex duties, but it is also one of the most significant to both organization and the employee. It is most important to the organization because wages and salaries often constitute the greatest single cost of doing business. It is important to employees because the pay check often is the sole means of economic survival.

In many cases, organizations prefer that their employees perform at a higher rate than average. If the goal of an organization is to attract capable employees, personnel department or human resource department must perceived that the compensation offered is fair and equitable.

Effective management of human resource depends upon an understanding of the dimension of human personality. Since employee job performance is largely depend upon factors in work environment that will release the potential of employees, the role of the motivational process deserves a special consideration.

In many cases, organizations prefer that their employees perform at a higher rate than average. If the goal of an organization is to attract capable employees, personnel department or human resource department must perceived that the compensation offered is fair and equitable.

Effective management of human resource depends upon an understanding of the dimension of human personality. Since employee job performance is largely depend upon factors in work environment that will release the potential of employees, the role of the motivational process deserves a special consideration. [1]

This study aimed to investigate the relationship between the adequacy of rewards and employee performance of large beverage companies specifically the Cosmos Bottling Corporation and Coca-Cola Bottlers Company,
Inc. which are situated in Valenzuela, Metro Manila and Meycauayan, Bulacan respectively. Specifically, this research study will answer the following sub-problems: Is there a significant difference between the respondent's perception of the adequacy of the type of rewards in their respective companies? Is there a significant relationship between the adequacy of rewards and employee performance as perceived by the respondents?

The following are the hypotheses of the study: There is no significant relationship between the adequacy of rewards and employee performance as perceived by the respondents. There is no significant difference in the adequacy of rewards as perceived by the Coca-cola and Cosmos employees.

\section{RESEARCH METHODOLOGY}

This study employed the descriptive method of research, which investigated the relationship between the adequacy of rewards and employee performance of exempt employees of Coca-Cola Bottlers Phils., Inc. and Cosmos Bottling Corporation. The total number of exempt employees of Coca-Cola Bottlers Phils., Inc. was 24 and the total number of exempt employees of Cosmos Bottling Corporation was 39. The number of respondents was determined by using the Slovin's formula. The researcher listed the name of the total number of population of the two companies and draw the name of respondents through lottery method of random sampling. The survey questionnaire was employed to gather data that determined the relationship between adequacy of rewards and employee performance as perceived by the respondents. The questionnaire was pretested to a group of respondents who were not included in the group of respondents. When the validity and clarity of the questionnaire were approved, 
the instrument was distributed and administered to the respondents.

In order to determine the perception of the respondents regarding the adequacy of rewards in their respective companies, the weighted was used. T-test was used to determine the significant difference in the perception of the respondents concerning the adequacy of rewards they receive. Furthermore, to determine the relationship between the adequacy of rewards and employee performance, Pearson R and T-test were used.

\section{RESULTS AND DISCUSSION}

The main objective of the research study is to investigate the relationship of the adequacy of rewards and employee performance and to determine if there is a significant difference in the perception of the respondents regarding the adequacy of rewards offered by their company. The presentation of the data in this chapter was of the same order as the statement of the problem. The data and numerical value were presented in a tabular form for easy and quick interpretation.

1. Weighted Mean of the Adequacy of Rewards As Perceived by Cosmos and Coca-Cola Employees. Table 1 showed the weighted mean of the adequacy of rewards as perceived by Cosmos and Coca-Cola employees. The Cosmos exempt employees revealed that the rewards offered by their company vary. Maternity subsidy has a weighted mean of 3.25 with a verbal interpretation of barely adequate; Sick leave and vacation leave is barely adequate with a weighted mean of 3.78; Service and loyalty award is 4.45 which means adequate. Perfect attendance awarding sick leave has a weighted mean of 3.12 which means barely adequate; sports program is 4.58 , which is adequate and educational assistance program is 4.56 interpreted as adequate. In thirteenth month pay, the weighted mean is 4.39 which means adequate; Incentive bonus is adequate with a weighted mean of 4.90; Miscellaneous benefits is 3.95 as barely adequate. Table 1 also showed that the weighted mean of uniform is 4.25 which means adequate; Employee of the year is 3 with a verbal interpretation of barely adequate; Medical-dental has a weighted mean of 3.12 which means barely adequate; Health care program is 4.58 which is adequate; Top sales supervisor has a weighted mean of 2.65 which means uncertain. SSS housing loan is 3.45; Educational loan is 3.69 and disability benefits with a verbal interpretation of barely adequate. Sickness benefits, maternity benefits, retirement benefits and death benefits are adequate with a weighted mean of 4.56, 4.82 and 4,63 respectively. Coca-cola exempt employees show that the adequacy of rewards offered by their company also vary. Maternity subsidy, with a weighted mean of 3.7 is interpreted as adequate, sick leave/vacation leave, with a weighted mean of 4.47 , very adequate, service and loyalty award is barely adequate with a weighted mean of 3.15 . Perfect attendance awarding sick leave, sports program and educational assistance program has a weighted mean of $3.63,3.67$ and 3.43 respectively with a verbal interpretation of adequate. Thirteenth month pay has a weighted mean of 4.5 which mean very adequate. Incentive bonus is adequate with a 3.53 weighted mean, miscellaneous benefits has a weighted mean of 2.83 interpreted as barely adequate. Furthermore, in terms of uniform, the exempt employees of coca-cola revealed that the reward is adequate with a 4.06 weighted mean. Employee of the year award and medical and dental is barely adequate as shown by its weighted mean which is equal to 2.76 and 3.9 respectively. Health care program is adequate with a weighted mean of 4.13. Top sales supervisor and SSS housing loan is barely adequate as shown by its weighted mean, 2.91 and 3.25. Educational loan, SSS salary loan, Sickness benefits, Maternity benefits, Disability benefits are adequate with a weighted mean of 3.65, 3.75, 4.06, 3.62, 3.67 and 3.88 respectively.

2. Difference in the Perception of Cosmos and Coca-Cola Employees in the Adequacy of Maternity Subsidy. Table 2 disclosed that there is no significant difference in the perception of Cosmos and Coca-Cola employees in the adequacy of maternity subsidy as it is evidenced by the result of the T-computed and the tabular value. The $t-$ computed is -1.08 which is less than the t-tabular value of 2.0 at .05 level of significance with 61 degree of freedom.

3. Difference in the Perception of Cosmos and Coca-Cola Employees in the Adequacy of Sick Leave/Vacation Leave. Table 3 showed that there is no significant difference in the perception of Cosmos and Coca-Cola employees in the adequacy of sick leave/vacation leave since the $t$ computed is -1.86 which is less than the t-tabular value of 2.0 at .05 level of significance with 61 degree of freedom.

4. Difference in the Perception of Cosmos and Coca-Cola Employees in the Adequacy of Service Loyalty Award. Table 4 revealed that there is a significant difference in the perception of Cosmos and Coca-Cola employees in the adequacy of service loyalty awards. The t-computed which is 2.96 is greater than the t-tabular value of 2.0 at .05 level of significance with 61 degree of freedom.

5. Difference in the Perception of Cosmos and Coca-Cola Employees in the Adequacy of Perfect Attendance Awarding Sick Leave. Table 5 showed that there is no significant difference in the perception of cosmos and coca-cola employees in the adequacy of perfect attendance awarding sick leave. The t-computed which is -1.98 is less than the t-tabular value of 2.0 at .05 level of significance with 61 degree of freedom.

6. Difference in the Perception of Cosmos and Coca-Cola Employees in the Adequacy of Sports Program. Table 6 disclosed that there is a significant difference in the perception of Cosmos and Coca-Cola employees in the adequacy of sports program. The t-computed which is 5.18 is greater than the t-tabular value of 2.0 at .05 level of significance with 61 degree of freedom.

7. Difference in the Perception of Cosmos and Coca-Cola Employees in the Adequacy of Educational Assistance 
system. Table 7 determined that there is a significant difference in the perception of Cosmos and Coca-Cola employees in the adequacy of educational assistance system. The t-computed which is 4.13 is greater than the t-tabular value of 2.0 at .05 level of significance with 61 degree of freedom.

8. Difference in the Perception of Cosmos and Coca-Cola Employees in the Adequacy of Thirteenth Month Pay. Table 8 determined that there is no significant difference in the perception of Cosmos and Coca-Cola employees in the adequacy of thirteenth month pay. The t-computed which is -0.76 is less than the t-tabular value of 2.0 at .05 level of significance with 61 degree of freedom.

9. Difference in the Perception of Cosmos and Coca-Cola Employees in the Adequacy of Incentive Bonus. Table 9 showed that there is a significant difference in the perception of Cosmos and Coca-Cola employees in the adequacy of incentive bonus. The $\mathrm{t}$-computed which is 8.83 is greater than the t-tabular value of 2.0 at .05 level of significance with 61 degree of freedom.

10. Difference in the Perception of Cosmos and CocaCola Employees in the Adequacy of Incentive Bonus. Table 10 disclosed that there is a significant difference in the perception of Cosmos and Coca-Cola employees in the adequacy of miscellaneous benefits. The t-computed which is 5.45 is greater than the t-tabular value of 2.0 at .05 level of significance with 61 degree of freedom.

11. Difference in the Perception of Cosmos and CocaCola Employees in the Adequacy of Uniforms. Table 11 showed that there is no significant difference in the perception of Cosmos and Coca-Cola employees in the adequacy of uniform. The t-computed which is 0.78 is less than the t-tabular value of 2.0 at .05 level of significance with 61 degree of freedom.

12. Difference in the Perception of Cosmos and CocaCola Employees in the Adequacy of Employee of the Year Award. Table 12 revealed that there is no significant difference in the perception of Cosmos and Coca-Cola employees in the adequacy of employee of the year award. The t-computed which is 0.67 is less than the t-tabular value of 2.0 at .05 level of significance with 61 degree of freedom.

13. Difference in the Perception of Cosmos and CocaCola Employees in the Adequacy of Medical-Dental Services. Table 13 disclosed that there is no significant difference in the perception of Cosmos and Coca-Cola employees in the adequacy of medical-dental services. The $\mathrm{t}$-computed which is -1.98 is less than the t-tabular value of 2.0 at .05 level of significance with 61 degree of freedom.

14. Difference in the Perception of Cosmos and CocaCola Employees in the Adequacy of Health Care Program. Table 14 showed that there is a significant difference in the perception of Cosmos and Coca-Cola employees in the adequacy of health care program. The $\mathrm{t}-$ computed which is 2.25 is greater than the t-tabular value of 2.0 at .05 level of significance with 61 degree of freedom.

15. Difference in the Perception of Cosmos and CocaCola Employees in the Adequacy of Top Sales Supervisor Award. Table 15 determined that there is no significant difference in the perception of Cosmos and Coca-Cola employees in the adequacy of top sales supervisor award. The t-computed which is -0.88 is less than the t-tabular value of 2.0 at .05 level of significance with 61 degree of freedom.

16. Difference in the Perception of Cosmos and CocaCola Employees in the Adequacy of SSS Housing Loan. Table 16 revealed that there is no significant difference in the perception of Cosmos and Coca-Cola employees in the adequacy of SSS housing loan. The t-computed which is 0.51 is less than the t-tabular value of 2.0 at .05 level of significance with 61 degree of freedom.

17. Difference in the Perception of Cosmos and CocaCola Employees in the Adequacy of Educational Loan. Table 17 established that there is no significant difference in the perception of Cosmos and Coca-Cola employees in the adequacy of educational loan. The t-computed which is 0.23 is less than the t-tabular value of 2.0 at .05 level of significance with 61 degree of freedom.

18. Difference in the Perception of Cosmos and CocaCola Employees in the Adequacy of Salary Loan. Table 18 disclosed that there is a significant difference in the perception of Cosmos and Coca-Cola employees in the adequacy of salary loan. The t-computed which is 2.51 is greater than the t-tabular value of 2.0 at .05 level of significance with 61 degree of freedom.

19. Difference in the Perception of Cosmos and CocaCola Employees in the Adequacy of Sickness Benefits. Table 19 showed that there is a significant difference in the perception of Cosmos and Coca-Cola employees in the adequacy of sickness benefits. The t-computed which is 3.37 is greater than the t-tabular value of 2.0 at .05 level of significance with 61 degree of freedom.

20. Difference in the Perception of Cosmos and CocaCola Employees in the Adequacy of Maternity Benefits Table 20 determined that there is a significant difference in the perception of Cosmos and Coca-Cola employees in the adequacy maternity benefits. The t-computed which is 3.90 is greater than the t-tabular value of 2.0 at .05 level of significance with 61 degree of freedom.

21. Difference in the Perception of Cosmos and CocaCola Employees in the Adequacy of Disability Benefits. Table 21 revealed that there is no significant difference in the perception of Cosmos and Coca-Cola employees in the adequacy disability benefits. The t-computed which is - 
2.16 is less than the t-tabular value of 2.0 at .05 level of significance with 61 degree of freedom.

22. Difference in the Perception of Cosmos and CocaCola Employees in the Adequacy of Retirement Benefits. Table 22 disclosed that there is no significant difference in the perception of Cosmos and Coca-Cola employees in the adequacy retirement benefits. The t-computed which is 0.94 is less than the t-tabular value of 2.0 at .05 level of significance with 61 degree of freedom.

23. Difference in the Perception of Cosmos and CocaCola Employees in the Adequacy of Death Benefits. Table 23 showed that there is a significant difference in the perception of Cosmos and Coca-Cola employees in the adequacy death benefits. The t-computed which is 2.25 is greater than the t-tabular value of 2.0 at .05 level of significance with 61 degree of freedom.

24. Relationship Between Rewards and Employee Performance of Cosmos Bottling Corporation. Table 24 illustrated that the computed Pearson $r$ is -0.372 which means that there is a slight negative linear relationship between the performance of Cosmos employees and the rewards. Since the t-computed which is 3.13 is greater than the tabular value of 2.0 at 0.05 level of significance with 61 degrees of freedom, the hypothesis that there is no significant relationship between rewards and employee performance of Cosmos Bottling Corporation is thus rejected. It means that there is a significant relationship between the adequacy of rewards and employee performance of Cosmos Bottling Corporation.

25. Relationship Between Rewards and Employee Performance of Coca-Cola Bottlers Phils., Inc. Table 25 showed that the computed Pearson $r$ is 0.368 which means that there is a slight positive linear relationship between the performance of Coca-cola employees and the rewards. Since the t-computed which is 3.09 is greater than the tabular value of 2.0 at 0.05 level of significance with 61 degrees of freedom, the hypothesis that there is no significant relationship between rewards and employee performance of Cosmos Bottling Corporation is thus rejected. It means that there is a significant relationship between the adequacy of rewards and employee performance of Coca-cola Bottlers Phils., Inc.

\section{CONCLUSION AND RECOMMENDATIONS}

The respondent employees of Cosmos revealed that the adequacy of rewards offered by their company ranged from barely adequate to adequate. Coca-Cola employees have also revealed that the adequacy of the rewards offered by the company are between adequate to very adequate.

There is a significant difference in the adequacy of the types of rewards given by the respective company. This reveals that the two groups of respondents have different perception in terms of the adequacy of rewards offered by the company.

The respondents revealed that the types of rewards given by Cosmos Bottling Corporation have a slight negative linear relationship. This means that there is a relationship between rewards and employee performance of Cosmos employees. The respondents of Coca-Cola also revealed that there is a slight positive relationship between rewards and employee performance. This shows that there is a significant relationship between rewards and employee performance of Coca-Cola employees.

In the light of the conclusion arrived at, the following are the recommendations.

1. Employees should be offered with rewards that will motivate them for better performance. The

employers should also improve the rewards which revealed barely adequate results due to the fact that these rewards have a significant relationship with the employee performance. 2. Employers should offer rewards which will develop the intellectual and professional skills of the employees. It has been concluded that there are only monetary rewards given by the company to the employees.

4. Continuous research studies must be undertaken to have an in-depth analyses of the factors, which affect employee performance such as:

a. Motivational factors for better performance of employees.

b. Rewards which will compensate and equate to the performance of employees.

c. Rewards which will increase the productivity of the employees.

\section{ACKNOWLEDGMENT}

I would like to extend my gratitude to my respondent beverage companies employees, to my friends who introduced me to this publication journal and to International Advanced Research Journal in Science and Engineering and Technology for giving me the opportunity to publish this research study.

\section{REFERENCES}

[1] Ivancevich, John M. (2010). Human Resources Management, Chicago: The McGraw-Hill Companies Inc., 305348349 ISBN:9780073381466

[2] Andres, T. Q. (1991). Developing Positive Behavior by Filipino Values. Manila: Divine Word Publications, 151-160

[3] Gohari, P., Ahmadloo, A., Bakhtiari, M. B. , Hosseinipour, S. J. The relationship between rewards and employee performance. (2013). Institute of Interdisciplinary Business Research, 543570.pdf. Retrieved from http://journal-archieves34.webs.com

[4] Yukl, Gary, (2013). Leadership in Organization, Prentice Hall, 117, 121, 127,

[5] Newstrom and Davis, (2002). Organizational Behavior: Human Behavior at Work, McGraw-Hill Education, 207, 208, 213, 215, 217, 218, 219.

[6] Sison, Perfecto S. (1991) Human Resources Management, Sixth Edition, Manila: Rex Book Store, 235, 297

[7] Njanja, W. L., Maina, R. N., Kibet, L. K., Kageni, N. (2013). Effect of reward on employeeperformance: A case of Kenya Power and Lighting Company Ltd., Nakuru, Kenya. International, Journal of Business and Management. Vol. 8, No. 21; 2013 ISSN 1833-3850 E-ISSN 1833-8119. Retrieved from http://www.ccsenet.org/journal

[8] Güngör, Pınar, (2011). The relationship between reward management system and employee performance with the mediating role of motivation: A quantitative study on global banks. Procedia Social and Behavioral Sciences, 24 (2011) 1510-1520. doi:10.1016/j.sbspro.2011.09.029

[9] Armstrong, Michael A. (2010). A Handbook of Management Technique, New Delhi: Excel Book, p203

[10] Chruden, Hubert J. and Arthur W. Sherman. (19980). Personnel Management: The Utilization of Human Resources, Manila: Mutual 
Book Store, 426-427 Daniels, Aubrey C. (2000). Bring Out The Best For People, New York: Mac Graw Hill, Inc., 148, 149, 173

[11] De la Cruz, R. (2000). Public Relations: Theory and Practice, Revised Edition, Manila: R.R. De la Cruz, 181-182,189

[12] Ali, Taskina; Akhter, Ireen (2009). Job Satisfaction of faculty members in private universities - in context of Bangladesh. International Business Research. Vol 2, No 4. Retrieved from www.ccsenet.org/journal.html

[13] Flippo, Edwin B. (2008). Personnel Management, Sixth Edition, Manila: National Book Store, 315, 327

[14] Andaya, Christina C. (1996). "Relationship of Job Satisfaction to the Job Performance of Engineers in the Construction Area of Metropolitan Waterworks and Sewerage System (MWSS)" (Unpublished special project, Polytechnic University of the Philippines)

[15] Ching, Vilma F. (1992). "Relationship Between Factors and Job Performance of Administrative Personnel at Quezon City Health Department" (Unpublished research project, Polytechnic University of the Philippines)

[16] Ismail, A., Zakaria, N. (2009). Relationship between interactional justice and pay for performance as an antecedent of job satisfaction: an empirical study in Malaysia. International Journal of Business and Management. Vol. 4, No. 3. Retrieved from http://www.ccsenet.org/journal

[17] Matteson, Ivancevich, (2002). Organizational Behavior and Management, Prentice-Hall, 109, 121, 188,189, 199, 201, 205, 206, 530, 533, 541

[18] Parvin, Mosammod Mahamuda (2011). Factors affecting employee job satisfaction of pharmaceutical sector. Australian Journal of Business and Management.Vol.1No.9[113-123].Retrievedfrom jbmr.com/articlepdf/AJBMR

[19] Rizwan, S., Mahmood, A., Mahmood, A. (2010). Effect of work motivation on job satisfaction in mobileteleco mmunication service organizations in Pakistan. International Journal of Business and Management. Vol 5, No 11 (2010). Retrieved from www.researchgate.net

20] Martires, Concepcion R. (2000). Management of Human Behavior in Organizations, Manila: National Book Store, 154, 188, 206, $215,216,223$

[21] Qureshi, M. I., Zaman, K., Shah, I. A., (2010). Relationship between rewards and employee's performance in the cement Industry in Pakistan. Journal of International Academic Research, Vol.10, No.2.Retrieved from http://www.academia.edu

Table 1

Weighted Mean of the Adequacy of Rewards

As Perceived by Cosmos and Coca-Cola Employees

\section{Rewards}

1. Car loan

2. Maternity subsidy

3. Sick leave/vacation leave

4. Service and loyalty award

5. Perfect attendance awarding sick leave

6. Sports program

7. Educational assistance

8. Thirteenth month pay

9. Incentive bonus

10. Miscellaneous benefit

11. Uniform

12. Employee of the year

13. Medical-dental

14. Health care program

15. Top sales supervisor

16. SSS housing loan

17. Educational loan

18. SSS salary loan

19. Sickness benefits

20. Maternity benefits

21. Disability benefits

22. Retirement benefits

23. Death benefits

\section{Cosmos}

Weighted Mean Verbal Interpretation

2.45 Uncertain

3.25 Barely adequate

3.78 Barely adequate

4.45 Adequate

3.12 Barely adequate

4.58 Adequate

4.56 Adequate

4.39 Adequate

4.90 Adequate

3.95 Barely adequate

4.25 Adequate

3.0 Barely adequate

3.12 Barely adequate

4.58 Adequate

2.65 Uncertain

3.45 Barely adequate

3.69 Barely adequate

4.87 Adequate

4.56 Adequate

4.83 Adequate

3.12 Barely adequate

4.02 Adequate

4.63 Adequate
Coca-Cola

Weighted Mean Verbal Interpretation

2.88 Barely adequate

3.7 Adequate

4.47 Very adequate

3.15 Barely adequate

3.63 Adequate

3.67 Adequate

3.43 Adequate

4.5 Very adequate

3.53 Adequate

2.83 Barely adequate

4.06 Adequate

2.76 Barely adequate

3.9 Barely adequate

4.13 Adequate

2.91 Barely adequate

3.25 Barely adequate

3.65 Adequate

3.75 Adequate

4.06 Adequate

4.18 Adequate

3.62 Adequate

3.67 Adequate

3.88 Adequate

Table 2

Difference in the Perception of Cosmos and Coca-Cola Employees in the Adequacy of Maternity Subsidy

\begin{tabular}{|c|c|c|c|c|c|}
\hline Company & Weighted Mean & Standard Deviation & t-computed & $\begin{array}{c}\text { Tabular Value } \\
\quad(\alpha .05)\end{array}$ & Decision \\
\hline \multirow[t]{2}{*}{ Cosmos } & 3.25 & 1.67 & & & \\
\hline & & & -1.08 & 2.0 & Accept Hc \\
\hline Coke & 3.70 & 1.49 & & & \\
\hline
\end{tabular}


Table 3

Difference in the Perception of Cosmos and Coca-Cola

Employees in the Adequacy of Sick Leave/Vacation Leave

$\begin{array}{llllcc}\text { Company } & \text { Weighted Mean } & \text { Standard Deviation } & \text { t-computed } & \begin{array}{c}\text { Tabular Value } \\ (\alpha .05)\end{array} & \text { Decision } \\ \text { Cosmos } & 3.78 & 1.75 & -1.86 & 2.0 & \text { Accept Ho }\end{array}$

Coke

0.62

Table 4

Difference in the Perception of Cosmos and Coca-Cola

Employees in the Adequacy of Service Loyalty Award

$\begin{array}{lllcc}\text { Company } & \text { Weighted Mean } & \text { Standard Deviation } & \text { t-computed } & \begin{array}{c}\text { Tabular Value } \\ (\alpha .05)\end{array} \\ \text { Cosmos } & 4.45 & 1.98 & \text { Decision }\end{array}$

Coke

3.15

1.07

2.96

Reject Ho

Table 5

Difference in the Perception of Cosmos and Coca-Cola Employees in the Adequacy of Perfect Attendance Awarding Sick Leave

$\begin{array}{lllccc}\text { Company } & \text { Weighted Mean } & \text { Standard Deviation } & \text { t-computed } & \begin{array}{c}\text { Tabular Value } \\ (\alpha .05)\end{array} & \text { Decision } \\ \text { Cosmos } & 3.12 & 1.05 & -1.98 & 2.0 & \text { Accept Ho }\end{array}$

Coke

0.89

Table 6

Difference in the Perception of Cosmos and Coca-Cola Employees in the Adequacy of Sport Program

\begin{tabular}{|c|c|c|c|c|c|}
\hline Company & Weighted Mean & Standard Deviation & t-computed & $\begin{array}{l}\text { Tabular Value } \\
\quad(\alpha .05)\end{array}$ & Decision \\
\hline \multirow[t]{2}{*}{ Cosmos } & 4.48 & 0.65 & & & \\
\hline & & & 5.18 & 2.0 & Reject Ho \\
\hline \multirow[t]{2}{*}{ Coke } & 3.67 & 0.72 & & & \\
\hline & \multicolumn{5}{|c|}{$\begin{array}{c}\text { Difference in the Perception of Cosmos and Coca-Cola Employees } \\
\text { in the Adequacy of Educational Assistance System }\end{array}$} \\
\hline Company & Weighted Mean & Standard Deviation & t-computed & $\begin{array}{l}\text { Tabular Value } \\
\quad(\alpha .05)\end{array}$ & Decision \\
\hline \multirow[t]{2}{*}{ Cosmos } & 4.56 & 1.12 & & & \\
\hline & & & 4.13 & 2.0 & Reject Ho \\
\hline \multirow[t]{2}{*}{ Coke } & 3.43 & 0.94 & & & \\
\hline & $\begin{array}{l}\text { Difference } \\
\text { Employees }\end{array}$ & $\begin{array}{l}\text { Table } 8 \\
\text { in the Perception of } \mathrm{C} \\
\text { in the Adequacy of }\end{array}$ & $\begin{array}{l}\text { s and Coca-C } \\
\text { eenth Month P }\end{array}$ & & \\
\hline Company & Weighted Mean & Standard Deviation & t-computed & $\begin{array}{l}\text { Tabular Value } \\
\quad(\alpha .05)\end{array}$ & Decision \\
\hline \multirow[t]{2}{*}{ Cosmos } & \multirow[t]{2}{*}{4.39} & 0.52 & & & \\
\hline & & & -0.76 & 2.0 & Accept Ho \\
\hline
\end{tabular}


Coke

Company

Cosmos

Coke

Company

Cosmos

Coke

Cosmos

Coke

Company

Cosmos

Coke

Company

Cosmos

Coke

Company

Cosmos
4.5

0.61

Table 9

Difference in the Perception of Cosmos and Coca-Cola Employees in the Adequacy of Incentive Bonus

Weighted Mean Standard Deviation t-computed

8.83

Tabular Value $(\alpha .05)$

2.0

Reject Ho
Table 10

Difference in the Perception of Cosmos and Coca-Cola

Employees in the Adequacy of Miscellaneous Benefits

Weighted Mean Standard Deviation

t-computed

0.25

5.45

1.25

Table 11

Difference in the Perception of Cosmos and Coca-Cola Employees in the Adequacy of Uniforms

Weighted Mean Standard Deviation

t-computed

0.85

0.78

Tabular Value $(\alpha .05)$

4.25

4.06

1.06

Table 12

Difference in the Perception of Cosmos and Coca-Cola Employees in the Adequacy of Employee of the Year Award

Weighted Mean Standard Deviation

t-computed

Tabular Value $(\alpha .05)$

2.76

1.20

Table 13

Difference in the Perception of Cosmos and Coca-Cola

Employees in the Adequacy of Medical-Dental Services

Weighted Mean Standard Deviation

t-computed

Tabular Value $(\alpha .05)$

1.78

3.9

0.94

$-1.98$

2.0

Accept Ho

Difference in the Perception of Cosmos and Coca-Cola Employees in the Adequacy of Health Care Program

Weighted Mean Standard Deviation t-computed

Tabular Value

Decision $(\alpha .05)$ 
Coke

Company

Cosmos

Coke

Company

Cosmos

Coke

Company

Cosmos

Coke

Company

Cosmos

Coke

Company

Cosmos

Coke

Company

Cosmos
4.13

0.74

Table 15

Difference in the Perception of Cosmos and Coca-Cola Employees in the Adequacy of Top Sales Supervisor Award

1.09

$$
-0.88
$$

Tabular Value $(\alpha .05)$

2.65

1.22

Table 16

Difference in the Perception of Cosmos and Coca-Cola Employees in the Adequacy of SSS Housing Loan

Weighted Mean Standard Deviation

t-computed

Tabular Value $(\alpha .05)$

1.69

0.51

Accept Ho

3.25

1.13

Table 17

Difference in the Perception of Cosmos and Coca-Cola Employees in the Adequacy of Educational Loan

Weighted Mean Standard Deviation t-computed

Tabular Value $(\alpha .05)$

Decision $3.69 \quad 0.59$

$$
0.23
$$

Accept Ho

Table 18

Difference in the Perception of Cosmos and Coca-Cola Employees in the Adequacy of Salary Loan

Weighted Mean Standard Deviation t-computed

Tabular Value

Decision $(\alpha .05)$
4.87
1.98

Reject Ho

3.75

1.18

Table 19

Difference in the Perception of Cosmos and Coca-Cola Employees in the Adequacy of Sickness Benefits
Weighted Mean Standard Deviation
t-computed

Tabular Value

Decision $(\alpha .05)$

$$
3.37
$$

Reject Ho
Table 20

Difference in the Perception of Cosmos and Coca-Cola Employees in the Adequacy of Maternity Benefits
Weighted Mean Standard Deviation

t-computed

0.55
Tabular Value $(\alpha .05)$
Decision

$4.82 \quad 0.55$




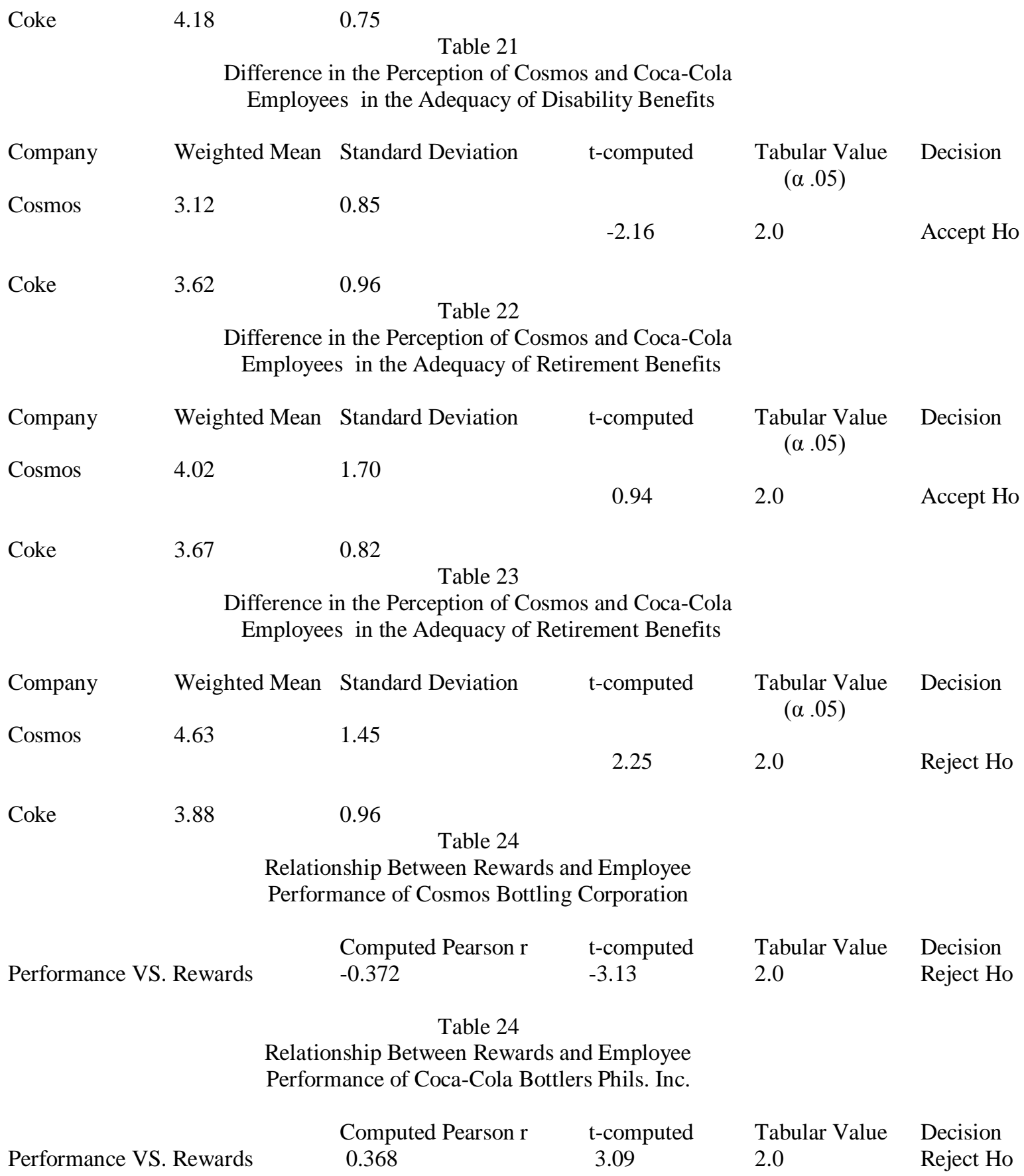

\section{BIOGRAPHY}

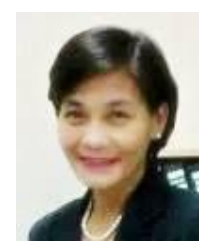

Dr. Felicidad A. Dy Kam completed her degree in Liberal Arts and Commerce major in Economics and Management from Ateneo de Naga University. She took her Master in Business Administration and Doctor in Business Administration from Polytechnic University of the Philippines. She has taught in various universities in the Philippines. She has also an international exposure abroad as visiting professor for 1 month in one of the universities in China and for two years as visiting professor in South Korea. Currently, she is working as an Assistant Professor at AMA International University-Bahrain where she handles Management and Economics subjects. 